\title{
COMPARATIVE STUDY OF MAXIMUM POWER POINT TRACKING TECHNIQUES FOR PHOTOVOLTAIC SYSTEMS
}

\author{
M. C. Cavalcanti, K. C. Oliveira, G. M. S. Azevedo, F. A. S. Neves \\ Department of Electric Engineering and Power systems, UFPE. Recife - PE - Brasil \\ Emails: marcelo.cavalcanti@ufpe.br, kleber_ufpe@yahoo.com.br, gustavomsa@netscape.net, fneves@ufpe.br
}

\begin{abstract}
This paper presents a comparative study among maximum power point tracking methods for photovoltaic systems. The comparison takes into account steady state error, dynamic response and efficiency in a large power range. In special, an extensive bibliography and a classification of many maximum power point tracking methods is presented. Computational simulations with fast changes in the solar irradiance have been done and the best maximum power point tracking technique is chosen. Experimental results corresponding to the operation of a photovoltaic converter controlled by a digital signal processor are also presented.
\end{abstract}

Keywords - Energy conversion, Photovoltaic power systems, Solar energy, Tracking.

\section{INTRODUCTION}

Nowadays, the requirement in generating electric energy has lead to an intensive research of alternative ways of generation. One of the possible ways of electric energy generation is the Photovoltaic (PV) energy. PV energy has great potential to supply energy, since it can be considered a clean and pollution free source while the PV panels are generating energy. The main drawbacks are associated with the impact on the environment because of the high energy used during the panels fabrication process and the lifetime of the panels that is between 20 and 30 years. Other drawbacks are the initial installation cost and the energy conversion efficiency. To overcome some of these problems, it is important to operate the photovoltaic system near the Maximum Power Point (MPP) to increase the efficiency of photovoltaic arrays. If Maximum Power Point Tracking (MPPT) techniques are used in PV systems, it can be generated more power with the same number of modules. These techniques allow the module generate its maximum power, having a high level of utilization of its generation capability. However, to improve the energy captation it is necessary to have a converter between the PV panels and the load or grid. This converter will have a limited and variable efficiency in according to the load conditions and the solar irradiance. Therefore the global efficiency (including PV array and converter efficiencies) is a better parameter for the whole system, but it would be necessary to compare the losses produced by the converter switches. The purpose of this paper is to compare the algorithms of maximum power point tracking and the converter efficiencies are not considered.

Manuscript received October 9, 2002; revised May, 2, 2003. This area will be used only by the Editor and Associate Editors. Please, the edition in this area is not permitted to the authors.
Various methods of MPPT have been considered in PV systems. The methods may be classified as: off-line techniques [1][2][3] and on-line techniques [4]-[27]. The off-line techniques require a PV array model and the measurement of temperature and solar irradiance. The on-line techniques do not require the measurement of temperature and solar irradiance. In addition, they do not need the PV array model.

Among the most desirable features in MPPT techniques are the following [6][7]:

- Stability

- Fast dynamic response

- Small steady state error

- Robustness to disturbances

- Efficiency in a large power range.

The on-line techniques have been shown as more efficient than the off-line techniques in terms of desirable features in MPPT methods. The on-line techniques may be classified as: Constant Voltage (CV), Perturbation and Observation (PO), and Incremental Conductance (IncCond). Some variations of these methods have been also presented in literature.

In [8], it was shown that the MPP voltage of a PV array is close to a fixed percentage of the array's open circuit voltage. In the MPPT technique, the converter is disconnected and the open circuit voltage is measured at regular sampling rates [9] [10]. The energy wasted by the sampling of the open circuit voltage is considered negligible in [11]. This method was defined as Constant Voltage (CV) technique in [9] and it has been used in some PV systems [10][11].

The PO method is often used in many PV systems [12][17]. PO techniques operate by perturbing the reference value with specific sampling rates [13]. These techniques present slow dynamic response and steady state error. A choice of high values of perturbation provides a fast tracking for the MPP voltage, but it has large oscillations. If the perturbation has a low value, the MPPT will be slower, but it will have small oscillations around the MPP. In addition, with fast changes of irradiance and temperature, the PO technique can track a wrong point. In [13], it was proposed an implementation of a PO method that instantaneous values of current and voltage are used to determine the direction of the next perturbation. This solution reduces the problems related to the PO techniques.

A popular variation of the PO method [14] is based on the relationship of the PV array output power and the switching duty cycle. This method is defined as the Hill Climbing (HC) technique in [15]. When it happens a fast variation in the environment conditions, it can be tracked a wrong voltage point instead of a point that means the MPP, creating an error in the algorithm. In other words, the algorithm will try 
to lead the array voltage to the MPP voltage of the curve corresponding to the previous solar irradiance. This problem can be also caused by a wrong choice of the sampling rate. A solution can be the best adjustment of the sampling rate [16] and the best adjustment of the perturbation (increment or decrement) in relation to the sampling rate [17], both in accordance with the dynamics of the converter. A Modified Adaptive Hill Climbing (MAHC) technique has automatic parameter tuning to satisfy the requirements of fast dynamic response and small steady state error [7].

The Incremental Conductance (IncCond) technique is widely used in PV systems [18]-[20]. The voltage of the MPP is tracked to satisfy $\mathrm{dP} / \mathrm{dV}=0$ [18]. The parasitic capacitance method uses the capacitances of the PV array to improve the IncCond technique [19]. A method which improves the IncCond technique by inserting a test signal in control input was proposed in [20].

In [21], it was proposed a technique that determines the MPP of a PV array for any temperature and solar irradiance using a tolerable power error. At each sample, the difference between the reference value and operating power of the PV array is calculated and compared with the assumed MPP error. A MPPT control scheme for PV array based on a principle of power equilibrium at dc link is proposed in [22]. The proposed scheme does not need detection or calculation of the power. A two-mode MPPT control method combining the $\mathrm{CV}$ and IncCond techniques was proposed to improve efficiency of the PV power generation systems at different irradiance conditions [23]. A method of locating the MPP based on injecting a small sinusoidal perturbation into the switching frequency and comparing the ac component and the average of the array terminal voltage was proposed in [24]. A MPPT method in combination with one-cycle control for PV power generation was proposed in [25]. In [26], it was used an algorithm with two stages of operation. In the first stage, variable large steps allow fast tracking when the PV voltage is far from the MPP voltage. Around the MPP voltage, any technique using fixed step can be used to track the MPP.

Due to the vast number of MPPT techniques with sometimes contradictory performance claims, their comprehensive study still seems to be appropriate. The algorithms have been verified on a PV system modeled in Matlab. Many simulations results are presented and the characteristics determined in this study are summarized in comparative tables.

\section{PHOTOVOLTAIC SYSTEM CONFIGURATIONS}

The PV array has the equivalent circuit shown in Fig. 1. Usually the shunt resistance is very large and the series resistance is very small [23]. Therefore, the resistances may be neglected to simplify the analysis. The characteristic of a PV array is given by the following equation [28]-[30]:

$$
I=I_{g}-I_{\text {sat }}\left[\exp \left(\frac{q}{A k T} V\right)-1\right]
$$

where $V$ is the PV array output voltage, $I$ is the PV array output current, $I_{g}$ is the generated current under a given irradiance, $I_{\text {sat }}$ is the reverse saturation current, $q$ is the

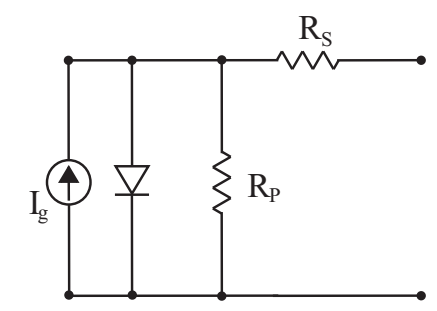

Fig. 1. Equivalent circuit of the PV array.

charge of an electron, $A$ is the ideality factor for a p$\mathrm{n}$ junction, $k$ is the Boltzmann's constant and $T$ is the temperature $(\mathrm{K})$.

The reverse saturation current and the generated current of the PV array vary with temperature in according to the following equations [23]:

$$
\begin{gathered}
I_{s a t}=I_{o r}\left[\frac{T}{T_{r}}\right]^{3} \exp \left[\frac{q E_{G 0}}{k T}\left(\frac{1}{T_{r}}-\frac{1}{T}\right)\right] \\
I_{g}=\left[I_{s c}+K_{I}\left(T-T_{r}\right)\right] \frac{S}{100}
\end{gathered}
$$

where $I_{o r}$ is the saturation current at $T_{r}, T_{r}$ is the reference temperature, $E_{G O}$ is the band-gap energy of the semiconductor used in array, $K_{I}$ is the short-circuit current temperature coefficient and $S$ is the irradiance in $\mathrm{mW} / \mathrm{cm}^{2}$.

Two systems were used to test the MPPT techniques. The first study is for a stand alone PV system using a $8.3 \mathrm{~kW}$ PV array consisting of twelve parallel connections of seven panels connected in series. Each of the solar panels has a maximum power rating of $99 \mathrm{~W}$, which occurs at a rated voltage of $17.7 \mathrm{~V}$ and a rated current of 5.6A. The panels have an open circuit voltage of $22 \mathrm{~V}$ and a short circuit current of $6.3 \mathrm{~A}$. The characteristic of the PV array is shown in Fig. 2 for variations in the solar irradiance (S). The PV array usually generates energy in low voltage and depending of the power to process, this characteristic can represent an inconvenient. In these cases a boost converter can be utilized because of its high efficiency and its small number of components [31][32]. Figure 3 presents the stand alone PV system using a boost converter. The second study is for a grid connected PV system using a $1.9 \mathrm{~kW}$ PV array consisting of twenty four panels connected is series. Each of the solar panels has a maximum power rating of $79 \mathrm{~W}$, which occurs at a rated voltage of $16.5 \mathrm{~V}$ and a rated current of $4.8 \mathrm{~A}$. The panels have an open circuit voltage of $20.8 \mathrm{~V}$ and a short circuit current of 5.2A. Both PV systems were tested in simulation by using Matlab and the grid connected PV system shown in Fig. 4 is also used to validate the simulation through the experimental results. The panels were modeled by using equations (1), (2) and (3).

\section{CONSTANT VOLTAGE}

The MPP voltage $\left(V_{M P P}\right)$ of a $\mathrm{PV}$ array is close to a fixed percentage of the PV array's open circuit voltage $\left(V_{O C}\right)$. The relation $V_{M P P} / V_{O C}$ is usually around $76 \%$ [8]. Initially, $V_{O C}$ is measured by setting the PV array current to be zero. In this way, the $V_{M P P}$ is adjusted for $76 \%$ of $V_{O C}$. This value of $V_{M P P}$ is kept for a period of time until another sample occurs. The MPPT technique samples $V_{O C}$ at regular 


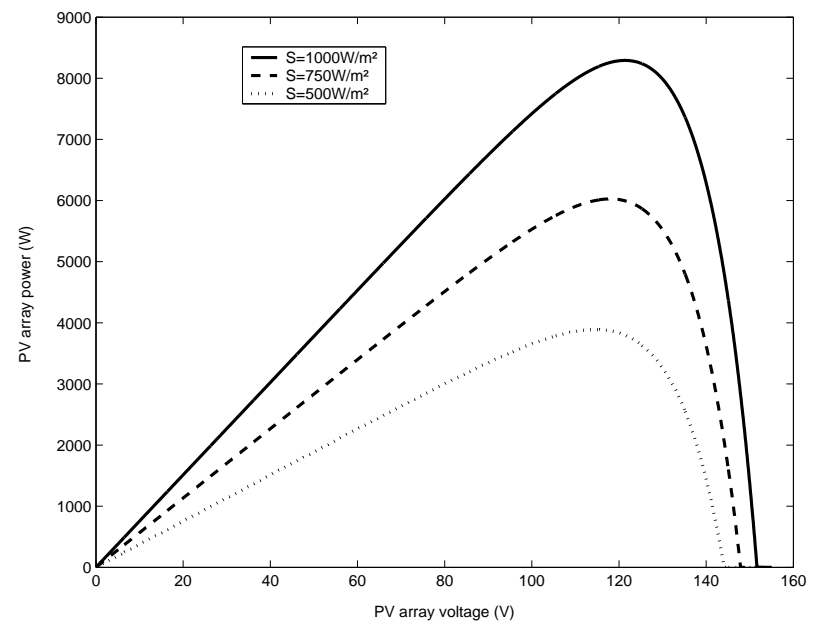

Fig. 2. Characteristic diagram of the PV array.

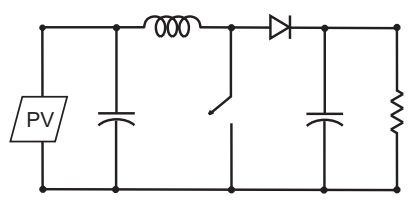

Fig. 3. Stand alone PV system using a boost converter.

samples [10] and the energy wasted by the sampling of $V_{O C}$ is considered negligible in [11]. However, this consideration should be evaluated. Another problem of this technique is that the MPP is not always located at $76 \%$ of the $V_{O C}$, increasing the steady state error [9]. Two different sample rates are used to estimate the efficiency. Using a low constant sample rate, the reference for $V_{M P P}$ is changed more frequently allowing better tracking while the system is connected to the PV array. However, the energy wasted by the sampling of $V_{O C}$ will be more significant since the PV array current will go to zero many times.

\section{PERTURBATION AND OBSERVATION}

The PO technique compares the power of the previous step with the power of the new step in such a way that

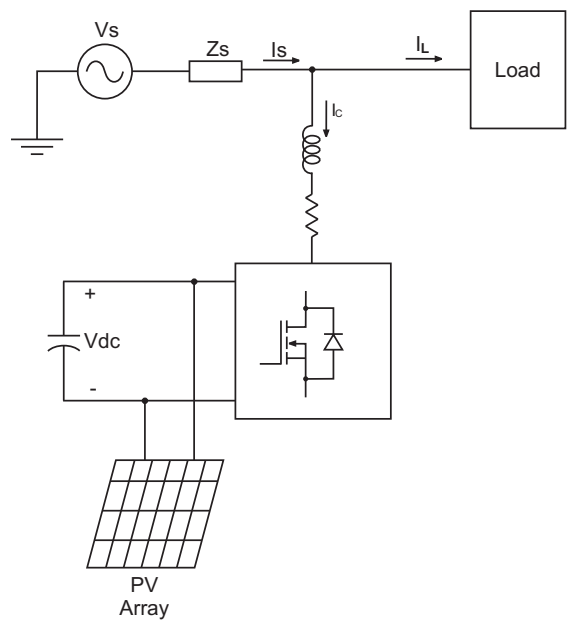

Fig. 4. Grid connected PV system using a three-phase inverter.

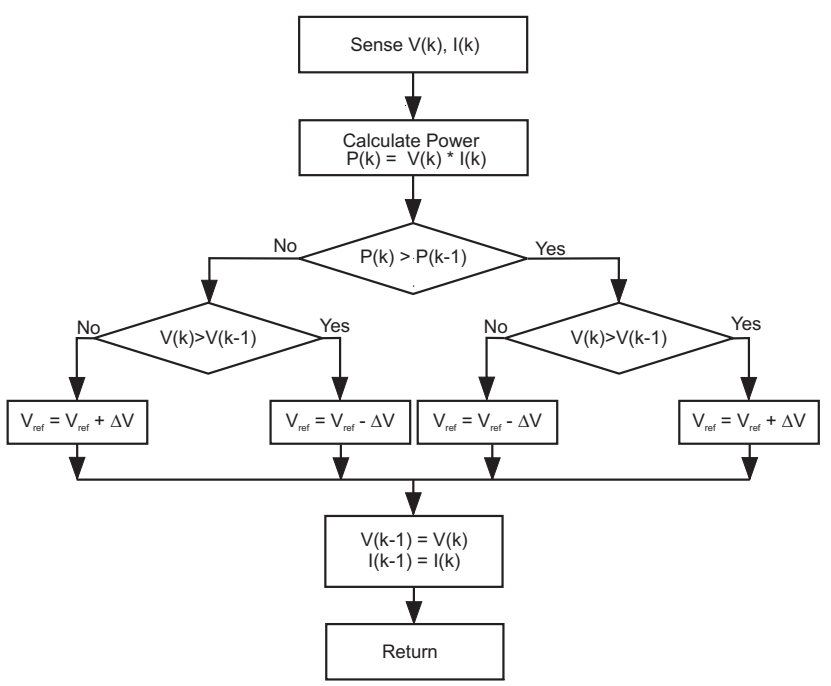

Fig. 5. The flowchart of the PO technique.

it can increase or decrease the voltage or current [12]-[17]. This method changes the reference value by a constant factor of current or voltage. It moves the operating point toward the MPP by periodically increasing or decreasing the array voltage or current. The PO method works well when the irradiance does not vary quickly with time. However, with this method the power oscillates around the MPP in steady state operation and it is not good when there are fast variations of temperature and irradiance.

The flowchart of the PO technique operating by varying the PV reference voltage is shown in Fig. 5 [12][13]. From Fig. 2, it can be seen that incrementing (decrementing) the voltage increases (decreases) the power when operating on the left of the MPP and decreases (increases) the power when on the right of the MPP. Therefore, if there is an increase in power, the subsequent perturbation should be kept the same to reach the MPP and if there is a decrease in power, the perturbation should be reversed [13]. A choice of high values of perturbation $(\Delta V)$ provides a fast tracking for the MPP voltage. If the perturbation has low value, the MPPT is slower, but it has small oscillations around the MPP.

The problem of oscillation around the MPP can be minimized by comparing the parameters of two preceding cycles. If the MPP is reached, the perturbation stage is bypassed [27]. This technique is named as Modified Perturbation and Observation (MPO) in this paper.

\section{HILL CLIMBING}

The HC method is based on the relationship of the PV array power and switching duty cycle [14]-[17]. The flowchart is shown in Fig. 6. Slope is a program variable with either 1 or -1 , indicating the direction to increase the output power, while "a"represents the increment step of duty cycle, which is a constant number between 0 and 1 , and $\mathrm{D}$ and $\mathrm{P}$ represent the duty cycle value for the switch in Fig. 3 and power level, respectively. With rapidly changing atmospheric conditions, the same problem of the PO can happen. The MAHC method includes automatic parameter tuning to have good dynamic 


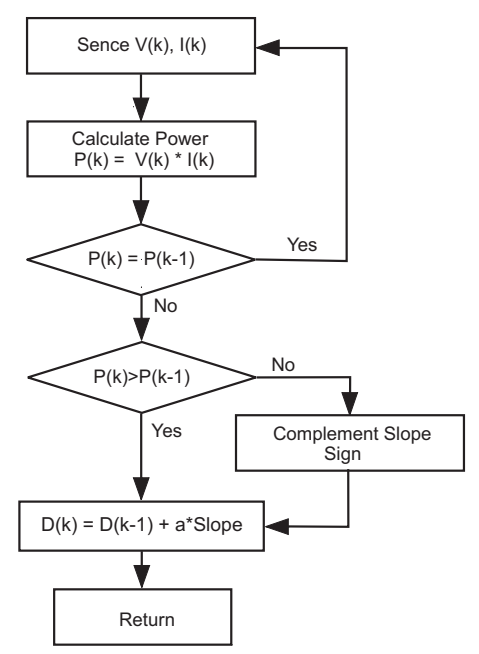

Fig. 6. The flowchart of the $\mathrm{HC}$ technique.

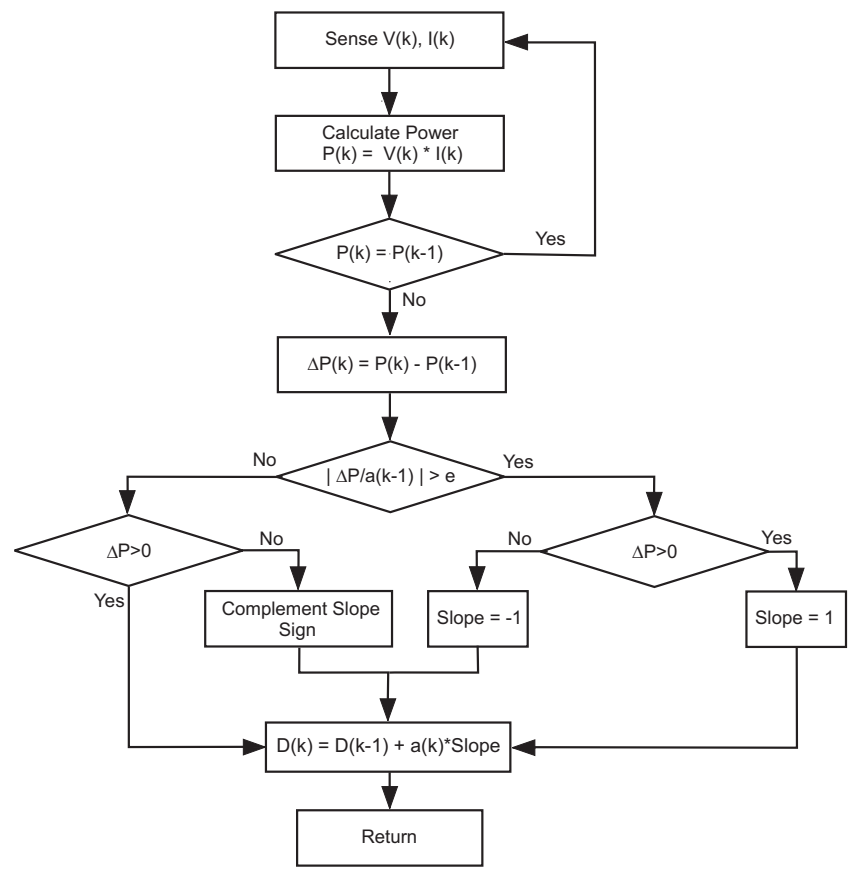

Fig. 7. The flowchart of the MAHC technique.

response and small steady state error [6]. The flowchart is shown in Fig. 7.

In the MAHC, two parameters make the controller flexible for different situations. The automatic parameter tuning uses:

$$
a(k)=M \frac{\Delta P}{a(k-1)}
$$

where $\Delta P$ is the change of power condition, a $(\mathrm{k}-1)$ is the historical value of $\mathrm{a}(\mathrm{k})$ and $\mathrm{M}$ is the constant parameter.

If $|\Delta P / a(k-1)|$ is larger than the threshold $e$, the controller understands that the power variation was caused by the solar irradiance and the duty cycle is changed in according to $\Delta P$. If $|\Delta P / a(k-1)|$ is smaller than $e$, the controller understands that the variation was caused by $a$ and the $\mathrm{HC}$ method is used.

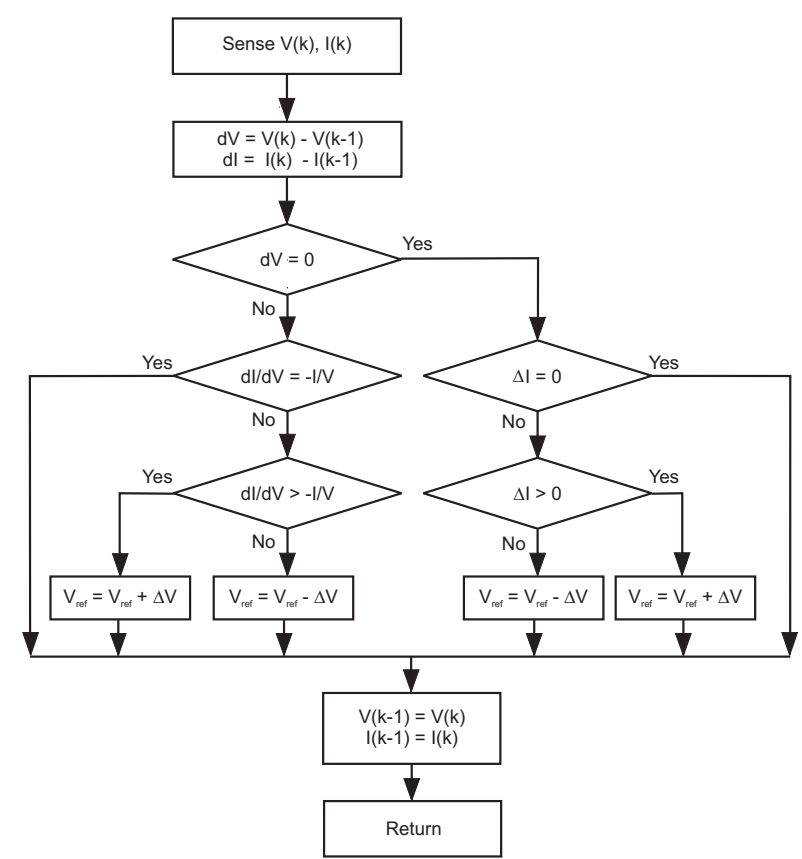

Fig. 8. The flowchart of the IncCond technique.

\section{INCREMENTAL CONDUCTANCE}

In the IncCond method [18]-[20], the slope of power versus voltage characteristic is used (Fig. 2) [18]. This technique decreases the oscillation problem and is easy to implement. Thus, in according with (5), it can be identified in which point of the curve the PV array voltage must be adjusted to reach the MPP voltage. The equation in the MPP is:

$$
\frac{d P}{d V}=0
$$

Or, it can be expressed as:

$$
\frac{d P}{d V}=\frac{d(I V)}{d V}=I+V \frac{d I}{d V}=0
$$

Hence, the array PV voltage can be adjusted rapidly to the MPP voltage by measuring the incremental and instantaneous array conductance $(d I / d V$ and $I / V$, respectively). In the method, (6) is used as the index of the maximum power point tracking operation (Fig. 2), where $S$ is the solar irradiance. When $d P / d V<0$, decreasing the reference voltage forces $d P / d V$ to approach zero; when $d P / d V>0$, increasing the reference voltage forces $d P / d V$ to approach zero; when $d P / d V=0$, reference voltage does not need any change. The flowchart is shown in Fig. 8. The IncCond uses fixed steps $(\Delta V)$ to increment the reference voltage.

\section{TOLERABLE POWER ERROR}

In [21], it was proposed a technique that determines the MPP of a PV array using a Tolerable Power Error (TPE). At each sample, the difference between the reference value and operating power of the PV array is calculated and compared with the assumed MPP error. The flowchart is shown in Fig. 9. If the difference is smaller than the acceptable error, the currently assigned values are maintained unchanged and taken 
as the PV array operating power. If the difference is greater than the acceptable error, the method searches the MPP. If the operating power $(\mathrm{P}(\mathrm{k}))$ is greater than the current MPP power value $(\mathrm{P}(\mathrm{k}-1))$, then $\mathrm{P}(\mathrm{k}), \mathrm{V}(\mathrm{k})$ and $\mathrm{I}(\mathrm{k})$ are assigned to $\mathrm{P}(\mathrm{k}-1)$, $\mathrm{V}(\mathrm{k}-1)$ and $\mathrm{I}(\mathrm{k}-1)$, respectively, as the new reference power point quantities for the next sampling. If $\mathrm{P}(\mathrm{k})$ is smaller than $\mathrm{P}(\mathrm{k}-1)$, then $\mathrm{V}(\mathrm{k})$ and $\mathrm{I}(\mathrm{k})$ are compared with $\mathrm{V}(\mathrm{k}-1)$ and $\mathrm{I}(\mathrm{k}-$ $1)$, respectively. If $\mathrm{V}(\mathrm{k})$ is smaller than $\mathrm{V}(\mathrm{k}-1)$ or $\mathrm{I}(\mathrm{k})$ é greater than $\mathrm{I}(\mathrm{k}-1)$, the operating power point values $\mathrm{P}(\mathrm{k}), \mathrm{V}(\mathrm{k})$ and $\mathrm{I}(\mathrm{k})$ are assigned as new reference MPP values. Otherwise, the algorithm continues with the current MPP values $\mathrm{P}(\mathrm{k}-1)$, $\mathrm{V}(\mathrm{k}-1)$ and $\mathrm{I}(\mathrm{k}-1)$.

\section{TWO STAGES}

This technique uses Two Stages (TS) of operation. In the first stage, variable large steps allow fast tracking when the PV voltage is far from the MPP voltage. The technique uses an intermediate variable $\beta$ [26]. The flowchart is shown in Fig. 10. If the PV array temperature is in a fixed range, $\beta$ at MPP is in a small fixed range. An appropriate range of $\beta$ can be specified for a given PV system for use with the algorithm. The upper limit $\left(\beta_{\max }\right)$ at MPP occurs in the maximum values of irradiance and temperature. The lower limit $\left(\beta_{\min }\right)$ at MPP occurs in the minimum values of irradiance and temperature. If $\beta$ is between $\beta_{\min }$ and $\beta_{\max }$, the operation is around the MPP voltage. In this case, the second stage with any technique using fixed step can be used to track the MPP. While implementing the first stage of the algorithm, $\beta_{g}$, the value of $\beta$ corresponding to the most probably array temperature is used as the guiding value for calculating the duty cycle correction as given as follows:

$$
\begin{gathered}
\text { error }=\beta_{g}-\beta_{a} \\
d_{\text {new }}=d_{\text {old }}+\text { error. } k
\end{gathered}
$$

where, $\beta_{a}$ is the actual value of $\beta$ at a given instant, $d_{\text {old }}$ and $d_{\text {new }}$ are the previous and the new duty cycle for the switch in Fig. 3, respectively, and $k$ is a constant corresponding to the $\beta$ plot.

\section{COMPARISON AMONG MPPT TECHNIQUES}

To compare the performances among the MPPT techniques, three desirable features are analyzed: dynamic response, steady state error and efficiency in a large power range.

Eight different techniques are compared: CV, PO, MPO, HC, MAHC, IncCond, TPE and TS. Some variations of these techniques are also tested in such a way that we have sufficient results to evaluate the data. In [16] and [17], it is shown that the efficiency of PO technique can be improved by optimizing its sampling rate and its duty cycle according to the converter's dynamics. Therefore variations in the sampling rates and in the perturbation values are also tested.

The dynamic response is evaluated by using two different irradiance changes. The changes from $500 \mathrm{~W} / \mathrm{m}^{2}$ to $1000 \mathrm{~W} / \mathrm{m}^{2}$ and from $1000 \mathrm{~W} / \mathrm{m}^{2}$ to $500 \mathrm{~W} / \mathrm{m}^{2}$ are used to represent the tracking time as shown in Table I. Steady state error is analyzed by measuring the averaged power and comparing with the ideal value for two irradiance conditions.

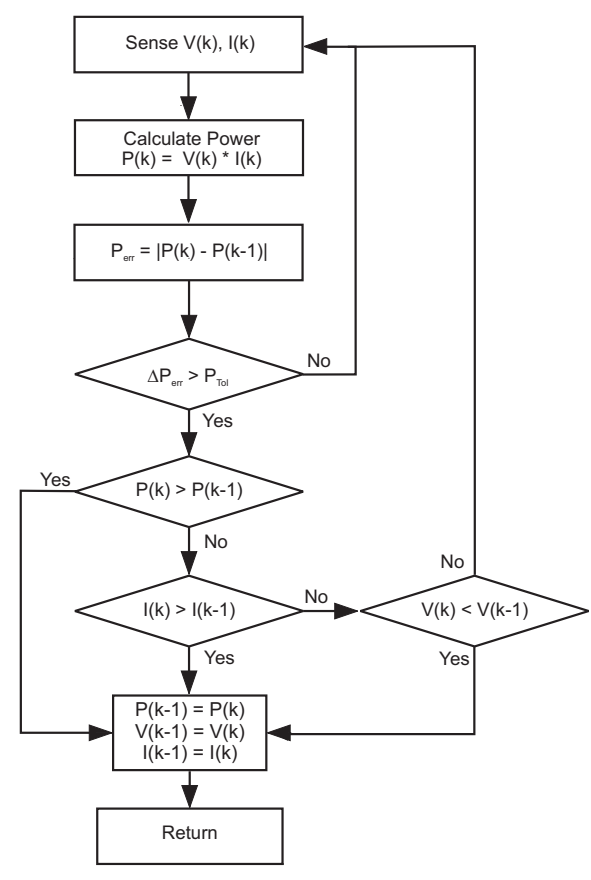

Fig. 9. The flowchart of the TPE technique.

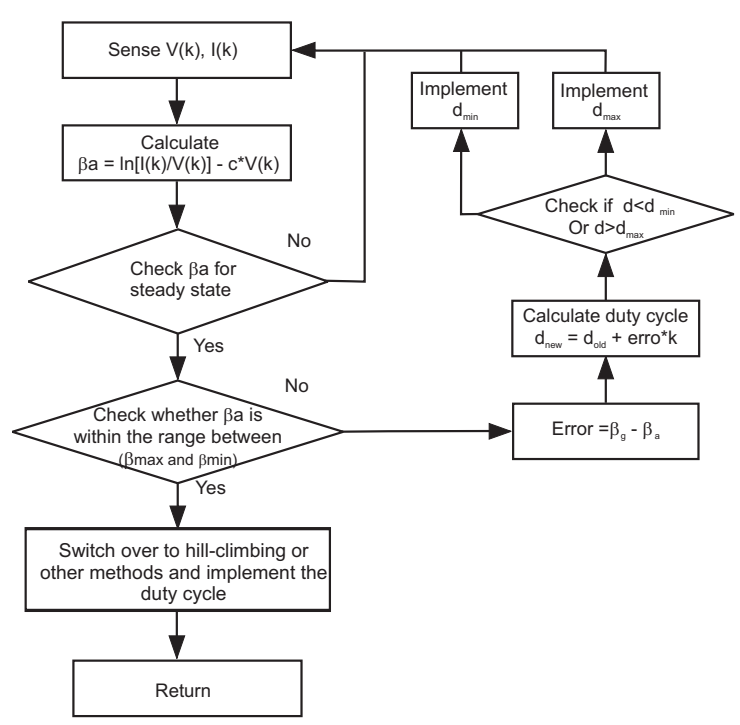

Fig. 10. The flowchart of the TS technique.

The maximum powers for the stand alone system (Fig. 3) with $500 \mathrm{~W} / \mathrm{m}^{2}$ and $1000 \mathrm{~W} / \mathrm{m}^{2}$ are $3889.5 \mathrm{~W}$ and $8292.9 \mathrm{~W}$, respectively, while the maximum powers for the grid connected system (Fig. 4) with $500 \mathrm{~W} / \mathrm{m}^{2}$ and $1000 \mathrm{~W} / \mathrm{m}^{2}$ are $1891.3 \mathrm{~W}$ and $880.4 \mathrm{~W}$, respectively.

Rates from $0.1 \mathrm{~ms}$ to $10 \mathrm{~s}$ are used to represent the effects of changing the sampling rates. In the $\mathrm{CV}$ method, the highest rates are used because sampling of $V_{O C}$. From Table I (stand alone system), it can be seen that the $\mathrm{CV}$ technique adjusts rapidly the array voltage to the reference voltage. However, the reference voltage is not exactly the voltage related to the MPP because the reference voltage is always $76 \%$ or $80 \%$ of the $V_{O C}$. The value of $80 \%$ for $V_{M P P} / V_{O C}$ was chosen because the specific PV array used in the simulations presents 
TABLE I

\section{Comparison among MPPT techniques}

\begin{tabular}{|c|c|c|c|c|}
\hline \multirow{2}{*}{$\begin{array}{c}\text { MPPT } \\
\text { Techniques } \\
\text { (Stand alone) }\end{array}$} & \multicolumn{2}{|c|}{ Tracking Time (ms) } & \multicolumn{2}{|c|}{ Power $(\mathbf{W})$} \\
\hline & $\begin{array}{c}\mathbf{S - 5 0 0} \text { to } \\
\mathbf{1 0 0 0} W / \mathrm{m}^{2}\end{array}$ & $\begin{array}{c}\mathbf{S - 1 0 0 0} \text { to } \\
\mathbf{5 0 0} W / m^{2}\end{array}$ & $\begin{array}{c}\mathbf{S - 5 0 0} \\
W / m^{2}\end{array}$ & $\begin{array}{l}\mathbf{S}-1000 \\
W / m^{2}\end{array}$ \\
\hline $\begin{array}{c}\text { CV - 80\% } \\
\text { Sampling 10s }\end{array}$ & - & 57 & 3888.5 & 8292.9 \\
\hline $\begin{array}{c}\mathrm{PO}-\Delta V=0.001 \\
\text { Sampling } 2 \mathrm{~ms}\end{array}$ & 43.4 & 96.7 & 3806.5 & 8292.2 \\
\hline $\begin{array}{c}\text { MPO - } \Delta V=0.05 \\
\text { Sampling } 2 \mathrm{~ms}\end{array}$ & 20.4 & 63.3 & 3815.0 & 8292.6 \\
\hline $\begin{array}{c}\mathrm{HC}-a=0.001 \\
\text { Sampling } 10 \mathrm{~ms}\end{array}$ & 56.4 & 8.9 & 3832.9 & 8287.0 \\
\hline $\begin{array}{l}\text { MAHC - } e=40 \\
\text { Sampling } 0.1 \mathrm{~ms}\end{array}$ & 5.3 & 5.2 & 3883.8 & 8289.8 \\
\hline $\begin{array}{c}\text { IncCond } \Delta V=0.2 \\
\text { Sampling } 1 \mathrm{~ms}\end{array}$ & 46.4 & 46.2 & 3889.4 & 8292.9 \\
\hline $\begin{array}{l}\text { TPE - Ptol }=90 \\
\text { Sampling } 0.5 \mathrm{~ms}\end{array}$ & 8.4 & - & 3875.4 & 8292.7 \\
\hline $\begin{array}{c}\text { TS }-k=1 \\
\text { Sampling } 0.1 \mathrm{~ms}\end{array}$ & 111.4 & 67.3 & 3887.2 & 8291.9 \\
\hline (Grid connected) & & & & \\
\hline $\begin{array}{c}\text { CV - 80\% } \\
\text { Sampling } 10 \mathrm{~s}\end{array}$ & 220 & 1170 & 880.4 & 1890.5 \\
\hline $\begin{array}{c}\mathrm{PO}-\Delta V=2 \\
\text { Sampling } 100 \mathrm{~ms}\end{array}$ & 1400 & - & 782.2 & 1891.0 \\
\hline $\begin{array}{c}\text { MPO - } \Delta V=2 \\
\text { Sampling } 100 \mathrm{~ms}\end{array}$ & 1000 & - & 800.9 & 1891.1 \\
\hline $\begin{array}{l}\text { IncCond } \Delta V=2 \\
\text { Sampling } 100 \mathrm{~ms}\end{array}$ & 1300 & 1400 & 874.4 & 1890.7 \\
\hline $\begin{array}{c}\text { TPE - Ptol }=1 \\
\text { Sampling } 100 \mathrm{~ms}\end{array}$ & 300 & 300 & 869.1 & 1886.5 \\
\hline
\end{tabular}

better results with this value instead of the $76 \%$ discussed before. The PO method with perturbations of $0.001 \mathrm{~V}$ has better steady state performance than PO with perturbations of $0.01 \mathrm{~V}$. The tracking time is small for both perturbations with the irradiance change from $500 \mathrm{~W} / \mathrm{m}^{2}$ to $1000 \mathrm{~W} / \mathrm{m}^{2}$. However, with irradiance change from $1000 \mathrm{~W} / \mathrm{m}^{2}$ to $500 \mathrm{~W} / \mathrm{m}^{2}$, the PO technique gives a wrong reference voltage and the controller can not track the MPP. The MPO technique presents a slightly improvement in the steady state performance because if the MPP is reached, the perturbation is not used. The HC method uses the duty cycle value for the switch in Fig. 3 to control the MPP. The system has one control loop with some oscillations around the MPP. However, using small steps (0.001 and 0.002) of duty cycle, this technique presents very good results. The IncCond technique presents good results of steady state and dynamic response regardless of the step and the sampling rate, being probably one of the most interesting MPPT techniques. The HC and IncCond techniques track the correct reference voltage even with the change from $1000 \mathrm{~W} / \mathrm{m}^{2}$ to $500 \mathrm{~W} / \mathrm{m}^{2}$. The TPE technique presents some problems when fast irradiance changes happen. This can be seen in Table I when the irradiance changes from $1000 \mathrm{~W} / \mathrm{m}^{2}$ to $500 \mathrm{~W} / \mathrm{m}^{2}$ and the controller can not track the MPP. On the other hand, this technique has good steady state performance. With the MAHC technique using variable steps in the duty cycle value for the switch in Fig. 3 , a good compromise between dynamic response and steady state performance can be obtained. Using variable steps to change the reference voltage, the algorithm has fast tracking with a large variable step when the PV voltage is far from the MPP voltage. Around the MPP voltage, the variable step is small. The TS technique uses the IncCond in the second stage (around the MPP).

Due to HC, MAHC and TS methods are based on the relationship of the PV array power and switching duty cycle of the boost converter, these methods are not used for comparisons in the grid connected system since the topology has only one three-phase inverter. Therefore, CV, PO, MPO, IncCond and TPE are chosen to continue the investigation. From Table I (grid connected system), it can be seen that PO and MPO methods can not track the reference when the irradiance changes from $1000 \mathrm{~W} / \mathrm{m}^{2}$ to $500 \mathrm{~W} / \mathrm{m}^{2}$ and this explains the low values of power for $S=500 \mathrm{~W} / \mathrm{m}^{2}$.

To test the efficiency of the techniques in the grid connected system, six different simulation curves for irradiance (power) are used. The first curve (Fig. 11) shows the power changing only twice, but the changes are fast. The second curve (Fig. 12) shows the power with many changes. In figures 11 and 12 , the irradiance is always within 800 and $1000 \mathrm{~W} / \mathrm{m}^{2}$. The third curve (Fig. 13) shows the power changing slowly and the fourth curve (Fig. 14) shows the power with some fast changes. In figures 13 and 14 , the irradiance is within 500 and $1000 \mathrm{~W} / \mathrm{m}^{2}$.

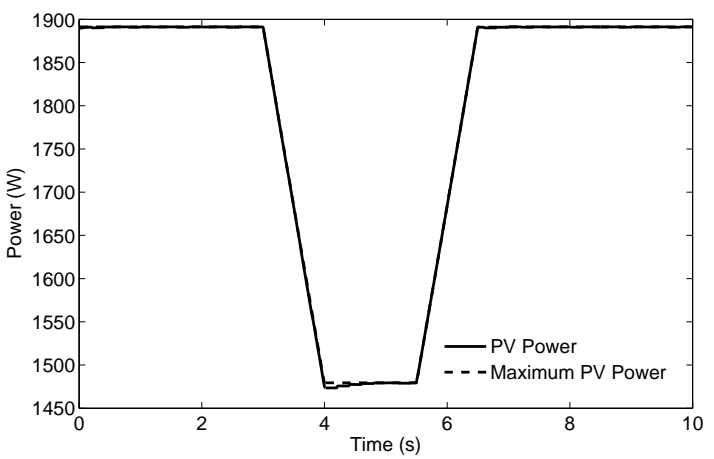

Fig. 11. First curve of irradiance for efficiency analysis.

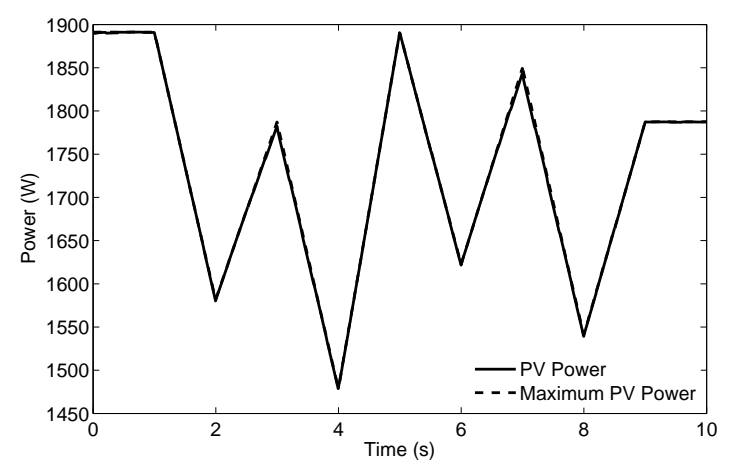

Fig. 12. Second curve of irradiance for efficiency analysis. 


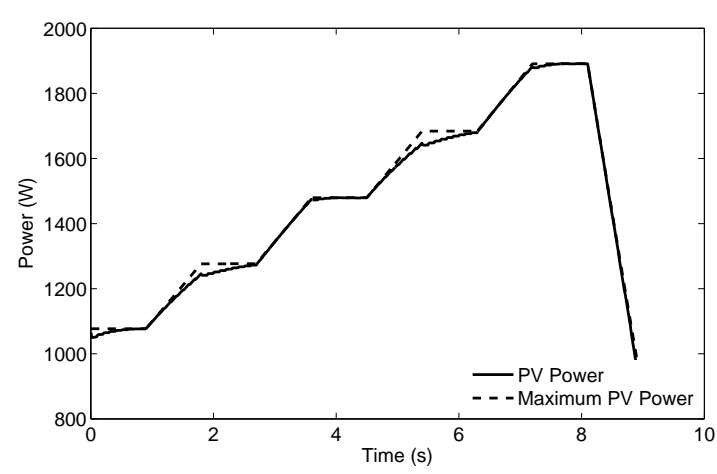

Fig. 13. Third curve of irradiance for efficiency analysis.

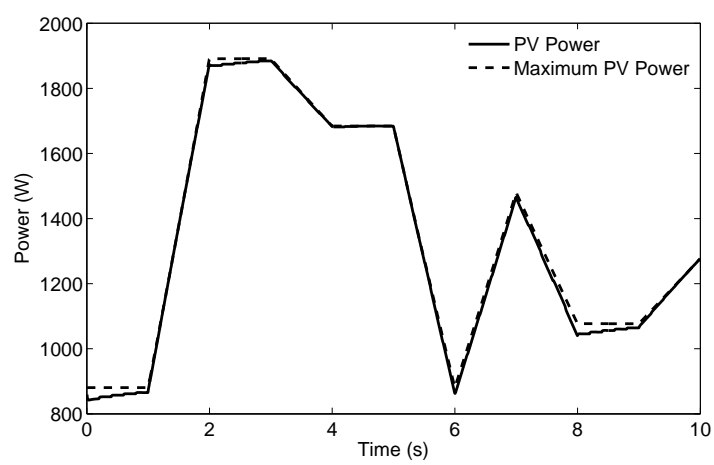

Fig. 14. Fourth curve of irradiance for efficiency analysis.

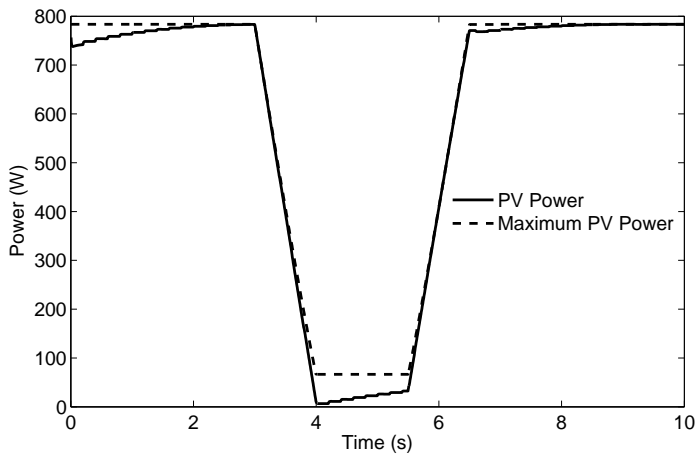

Fig. 15. Fifth curve of irradiance for efficiency analysis.

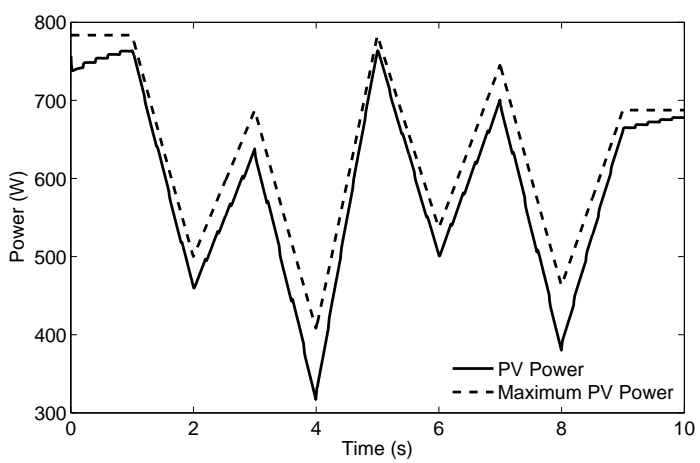

Fig. 16. Sixth curve of irradiance for efficiency analysis.
TABLE II

Efficiency in the grid connected system (Fig. 4)

\begin{tabular}{cccccc}
\hline $\begin{array}{c}\text { Curves of } \\
\text { irradiance }\end{array}$ & CV & PO & MPO & IncCond & TPE \\
\hline Fig. 11 & 99.95 & 96.00 & 99.31 & 99.97 & 99.88 \\
\hline Fig. 12 & 99.98 & 99.95 & 99.71 & 99.93 & 99.93 \\
\hline Fig. 13 & 99.76 & 92.93 & 98.39 & 99.38 & 99.35 \\
\hline Fig. 14 & 99.49 & 91.10 & 97.58 & 99.12 & 99.13 \\
\hline Fig. 15 & 93.21 & 76.07 & 82.27 & 97.51 & 94.85 \\
\hline Fig. 16 & 93.71 & 77.11 & 86.10 & 93.55 & 93.78 \\
\hline
\end{tabular}

To continue the investigation, the best techniques are tested under low irradiance conditions. To test the efficiency of the techniques under low irradiance, the curves in Fig. 15 and Fig. 16 are used. In figures 11-16 the measured irradiance values were used to find the theoretical MPP values (PV Maximum Power), which were compared with the measured MPP values (PV power) for the IncCond method. The different situations (Table II) are useful to estimate which technique has the best efficiency independent of the way that the irradiance changes. The efficiency $(\eta)$ is defined as:

$$
\eta=\frac{\int P d t}{\int P_{\max } d t}
$$

where $P$ is the PV array output power and $P_{\max }$ is the PV array maximum power.

In Table II, all methods use the same condition shown in Table I. CV, IncCond and TPE techniques present good results, but the IncCond method presents high efficiencies for all curves even with small changes in the sampling time and increment, being considered as the most robust technique. Therefore this technique is chosen as the best MPPT technique for the situations shown in figures 11 to 16. However, with different conditions, other MPPT techniques can present the best efficiency. This happens because the MPPT techniques have different performances when changing the irradiance and temperature of the PV array. In addition, the sampling rate, the increment of the reference and the converter used to connect the PV array to the load have strong influence on the performance of the technique.

\section{EXPERIMENTAL RESULTS}

The experimental results were obtained by using power measurements in the real ambient conditions and therefore it is not possible to have the same curves (figures 11 to 16) used in the simulations results. The grid connected PV system shown in Fig. 4 is used to validate the simulation results with the following procedure: from 0 to $7.5 \mathrm{~s}$, the reference voltage is changed to build the PV array power curve. From 7.5 s to $50 \mathrm{~s}$, a MPPT method is used to track the maximum power point. Simulation and experimental results for PO and IncCond methods are shown in figures 17 and 18, respectively. Similar results were obtained for CV, MPO and TPE methods. In these figures, the average power in simulation is around $1489 \mathrm{~W}$ and it was verified by using 

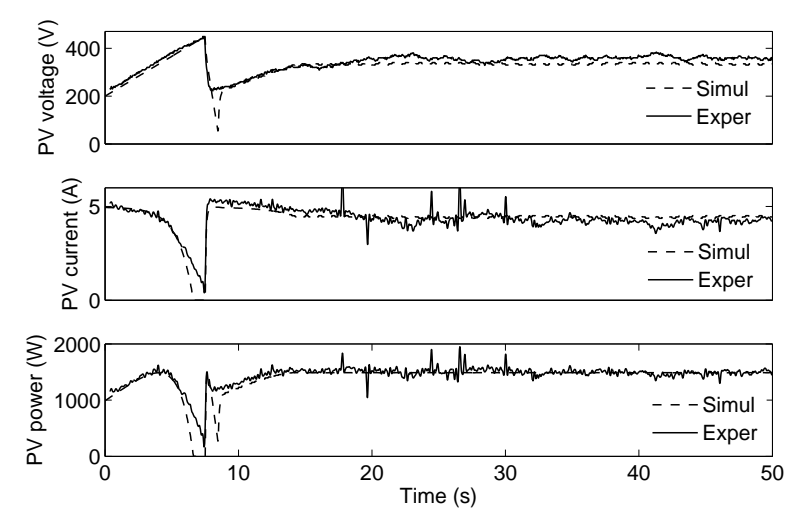

Fig. 17. Simulation and experimental results for PO method.
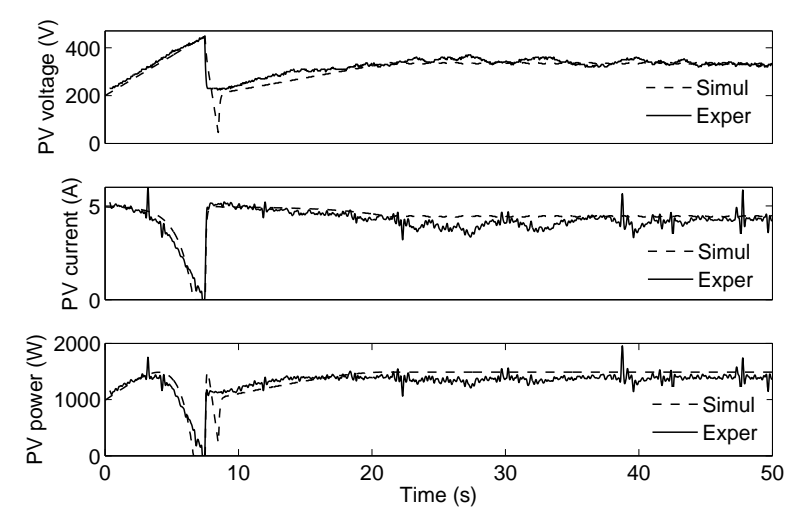

Fig. 18. Simulation and experimental results for IncCond method.

a irradiance measurement that the irradiance was constant during the data acquisition process. It can be seen a very good agreement between simulation and experiment, showing that the PV array model used for comparisons among the MPPT techniques is valid.

\section{CONCLUSION}

Researchers continue to make an effort to control the photovoltaic array near to the maximum power point. This paper has classified the maximum power point tracking techniques in terms of the way that the reference variable is changed. Principles of operation and main features have been discussed for a better understanding of each possibility. Tables summarize the simulation results and the IncCond technique has presented the best results for the different situations tested in this paper. A comparative study on losses in the converter is under study to complete this scenario that is expected to aid the engineers in the preliminary stages of maximum power point tracking techniques selection and analysis.

\section{REFERENCES}

[1] B. K. Bose et al, Microcomputer control of a residential photovoltaic power conditioning system, IEEE Trans. on Industry Applications, vol. 21, no. 5, pp. 1182-1191, September 1985.
[2] J. Appelbaum, The operation of loads powered by separate sources or by a common source of solar cells, IEEE Trans. on Energy Conversion, vol. 4, no. 3, pp. 351-357, September 1989.

[3] J. Appelbaum and M. S. Sarma, The operation of permanent magnet DC motors powered by a common source of solar cells, IEEE Trans. on Energy Conversion, vol. 4, no. 4, pp. 635-642, December 1989.

[4] O. Wasynczuk, Dynamic behavior of a class of photovoltaic power systems, IEEE Trans. on Power Apparatus and Systems, vol. 102, no. 9, pp. 3031-3037, September 1983.

[5] F. Harashima et al, Microprocessor-controlled SIT inverter for solar energy system, IEEE Trans. on Industrial Electronics, vol. 34, no. 1, pp. 50-55, February 1987.

[6] W. Xiao and W. G. Dunford, A modified adaptive hill climbing MPPT method for photovoltaic power systems, IEEE Power Electronics Specialists Conference, pp. 19571963, 2004.

[7] Y. C. Kuo, T. J. Liang, and J. F. Chen, Novel maximum power-point-tracking controller for photovoltaic energy conversion system, IEEE Trans. on Industrial Electronics, vol. 48, no. 3, pp. 594-601, June 2001.

[8] J. J. Schoeman and J. D. van Wyk, A simplified maximal power controller for terrestrial photovoltaic panel arrays, IEEE Power Electronics Specialists Conference, pp. 361367, 1982.

[9] D. P. Hohm and M. E. Ropp, Comparative study of maximum power point tracking algorithms using an experimental, programmable, maximum power point tracking test bed, IEEE Photovoltaic Specialists Conference, pp. 1699-1702, 2000.

[10] A. S. Kislovski, Power tracking methods in photovoltaic applications, IEEE Power Conversion Proceedings, pp. 513-528, 1993.

[11] W. Swiegers and J. H. R. Enslin, An Integrated maximum power point tracker for photovoltaic panels, IEEE International Symposium on Industrial Electronics, pp. 40-44, 1998.

[12] C. Hua, J. Lin, and C. Shen, Implementation of a DSPcontrolled photovoltaic system with peak power tracking, IEEE Trans. on Industrial Electronics, vol. 45, no. 1, pp. 99-107, February 1998.

[13] X. Liu and L. A. C. Lopes, An improved perturbation and observation maximum power point tracking algorithm for PV arrays, IEEE Power Electronics Specialists Conference, pp. 2005-2010, 2004.

[14] E. Koutroulis, K. Kalaitzakis, and N. C. Voulgaris, Development of a microcontroller-based, photovoltaic maximum power point tracking control system, IEEE Trans. on Power Electronics, vol. 16, no. 1, pp. 46-54, January 2001.

[15] T. Senjyu and K. Uezato, Maximum power point tracker using fuzzy control for photovoltaic arrays, IEEE International Conference on Industrial Technology, pp. 143-147, 1994.

[16] N. Femia, G. Petrone, G. Spagnuolo, and M. Vitelli, Optimizing sampling rate of PO MPPT technique, IEEE 
Power Electronics Specialists Conference, pp. 1945-1949, 2004.

[17] N. Femia, G. Petrone, G. Spagnuolo, and M. Vitelli, Optimizing duty-cycle perturbation of PO MPPT technique, IEEE Power Electronics Specialists Conference, pp. 19391944, 2004.

[18] K. H. Hussein, I. Muta, T. Hoshino, and M. Osakada, Maximum photovoltaic power tracking: an algorithm for rapidly changing atmospheric conditions, IEE Proc. Generation, Transmission and Distribution, vol. 142, pp. 59-64, Jan. 1995.

[19] A. Brambilla, New approach to photovoltaic arrays maximum power point tracking, IEEE Power Electronics Specialists Conference, pp. 632-637, 1998.

[20] T. Y. Kim, H. G. Ahn, S. K. Park, and Y. K. Lee, A novel maximum power point tracking control for photovoltaic power system under rapidly changing solar radiation, IEEE International Symposium on Industrial Electronics, pp. 1011-1014, 2001.

[21] I. H. Altas and A. M. Sharaf, A novel on-line MPP search algorithm for PV arrays, IEEE Trans. on Energy Conservation, vol. 11, no. 4, pp. 748-754, December 1996.

[22] M. Matsui, T. Kitano, D. Xu, and Z. Yang, A new maximum photovoltaic power tracking control scheme based on power equilibrium at DC link, IEEE Industry Applications Conference, pp. 804-809, 1999.

[23] G. J. Yu, Y. S. Jung, J. Y. Choi, I. Choy, J. H. Song, and G. S. Kim, A novel two-mode MPPT control algorithm based on comparative study of existing algorithms, IEEE Photovoltaic Specialists Conference, pp. 1531-1534, 2002.

[24] K. K. Tse, M. T. Ho, H. S. H. Chung, and S. Y. Hui, A novel maximum power power point tracker for PV panels using switching frequency modulation, IEEE Trans. on Power Electronics, vol. 17, no. 6, pp. 980-989, November 2002.

[25] Y. Chen, K. Smedley, F. Vacher, and J. Brouwer, A new maximum power point tracking controller for photovoltaic power generation, IEEE Applied Power Electronics Conference and Exposition, pp. 58-62, 2003.

[26] S. Jain and V. Agarwal, A new algorithm for rapid tracking of approximate maximum power point in photovoltaic systems, IEEE Power Electronics Letters, vol. 2, no.1, pp. 16-19, May/June 2004.

[27] K. H. Hussein and I. Muta, Modified algorithms for photovoltaic maximum power point tracking, Joint Conference of Electrical and Electronics Engineers in Kyushu, Japan, pp. 301, 1991.

[28] C. Hua and C. Shen, Comparative study of peak power tracking techniques for solar storage systems, IEEE Applied Power Electronics Conference and Exposition, pp. 679-685, 1998.

[29] M. Park, B. T. Kim, and I. K. Yu, A novel simulation method for PV power generation systems using real weather conditions, IEEE International Symposium on
Industrial Electronics, pp. 526-530, 2001.

[30] Y. C. Kuo, T. J. Liang, and J. F. Chen, A high-efficiency single-phase three-wire photovoltaic energy conversion system, IEEE Trans. on Industrial Electronics, vol. 50, no. 1, pp. 116-122, February 2003.

[31] P. Shanker and J. M. S. Kim, A new current programming technique using predictive control, IEEE 16th International Telecommunications Energy Conference, pp. 428-434, 1994.

[32] C. Hua and C. Shen, Control of DC/DC converters for solar energy system with maximum power tracking, International Conference on Industrial Electronics, Control and Instrumentation, pp. 827-832, 1997.

\section{BIOGRAPHIES}

Marcelo Cabral Cavalcanti was born in Recife, Brazil, in 1972. He received the B.S. degree in electrical engineering in 1997 from the Federal University of Pernambuco, Recife, Brazil, and the M.S. and Ph.D. degrees in electrical engineering from the Federal University of Campina Grande, Campina Grande, Brazil, in 1999 and 2003, respectively. Since 2003, he has been at the Electrical Engineering and Power Systems Department, Federal University of Pernambuco, where he is currently a Professor of Electrical Engineering. His research interests are power electronics, renewable systems and power quality.

Kleber Carneiro de Oliveira was born in Recife, Brazil, in 1980. He received the B.S. and M.S. degrees in electrical engineering from the Federal University of Pernambuco, Recife, Brazil, in 2005 and 2007, respectively, where he is currently working toward the Ph.D. degree in electrical engineering. He has worked with the Power Electronics and Electrical Drives Group of the Federal University of Pernambuco. His research interest is power electronics and renewable energy.

Gustavo Medeiros de Souza Azevedo was born in Belo Jardim, Brazil, in 1981. He received the B.S. degree in electrical engineering in 2006 from the Federal University of Pernambuco, Recife, Brazil, where he is currently working toward the M.S. degree in electrical engineering. He has worked with the Power Electronics and Electrical Drives Group of the Federal University of Pernambuco. His research interests are power electronics and renewable energy systems.

Francisco de Assis dos Santos Neves was born in Campina Grande, Brazil, in 1963. He received the B.S. and M.S. degrees in electrical engineering in from the Federal University of Pernambuco, Recife, Brazil, in 1984 and 1992, respectively, and the $\mathrm{Ph} . \mathrm{D}$. degree in electrical engineering in 1999 from the Federal University of Minas Gerais, Belo Horizonte, Brazil. Since 1993, he has been at the Electrical Engineering and Power Systems Department, Federal University of Pernambuco, where he is currently a Professor of Electrical Engineering. His research interests are power electronics, renewable systems and power quality. 